University of Nebraska - Lincoln

DigitalCommons@University of Nebraska - Lincoln

4-15-1995

\title{
Microstructure of the $\mathrm{Cr}$ underlayer and its effect on $\mathrm{Sm}-\mathrm{Co} / / \mathrm{Cr}$ thin films
}

Yi Liu

University of Nebraska-Lincoln, yliu@unl.edu

B. W. Robertson

University of Nebraska-Lincoln, brobertson1@unl.edu

Z.S. Shan

University of Nebraska - Lincoln

Sy_Hwang Liou

University of Nebraska-Lincoln, sliou@unl.edu

David J. Sellmyer

University of Nebraska-Lincoln, dsellmyer@unl.edu

Follow this and additional works at: https://digitalcommons.unl.edu/physicsliou

Part of the Physics Commons

Liu, Yi; Robertson, B. W.; Shan, Z.S.; Liou, Sy_Hwang; and Sellmyer, David J., "Microstructure of the Cr underlayer and its effect on Sm-Co//Cr thin films" (1995). Si-Hwang Liou Publications. 54.

https://digitalcommons.unl.edu/physicsliou/54

This Article is brought to you for free and open access by the Research Papers in Physics and Astronomy at DigitalCommons@University of Nebraska - Lincoln. It has been accepted for inclusion in Si-Hwang Liou Publications by an authorized administrator of DigitalCommons@University of Nebraska - Lincoln. 


\title{
Microstructure of the $\mathrm{Cr}$ underlayer and its effect on $\mathrm{Sm}-\mathrm{Co} / / \mathrm{Cr}$ thin films
}

\author{
Y. Liu and B. W. Robertson \\ Center for Materials Research and Analysis, and Mechanical Engineering Department, University of \\ Nebraska-Lincoln, Lincoln, Nebraska 68588 \\ Z. S. Shan, S. H. Liou, and D. J. Sellmyer \\ Center for Materials Research and Analysis, and Behlan Laboratory of Physics, University of Nebraska- \\ Lincoln, Lincoln. Nebraska 68588
}

(Received 8 August 1994; accepted for publication 19 December 1994)

\begin{abstract}
$\mathrm{Sm}-\mathrm{Co}$ film is a potential candidate for the future high density recording media of $10 \mathrm{~Gb} / \mathrm{in}^{2}$ which requires bit sizes of the order of $300 \mathrm{~nm}$ and grain sizes of about $10 \mathrm{~nm}$. This article investigates the microstructure of the $\mathrm{Cr}$ underlayer in $\mathrm{Sm}$-Co thin films and its effect on Sm-Co thin films prepared by the dc magnetron sputtering technique. The grain size of the $\mathrm{Cr}$ underlayer is found to be about $25 \mathrm{~nm}$. Grains with small angle misorientation usually form local agglomerates. Studies by transmission electron microscopy (TEM) bright field images at different defocus settings and by high resolution electron microscopy indicate that a large proportion of the grain boundaries have gaps. The gap width (about 1-3 nm) varies from place to place. The Sm-Co films deposited on the $\mathrm{Cr}$ underlayer inherit similar gaps at positions adjacent to the grain boundary gaps of the $\mathrm{Cr}$ underlayer. Such gaps produce grain-like contrast of about $25 \mathrm{~nm}$ in TEM bright field images. However, such contrast becomes weak as the thickness of the film increases and disappears at a thickness of $96 \mathrm{~nm}$, suggesting the gaps are sealed at places far from the Cr underlayer. The effect of the $\mathrm{Cr}$ underlayer on magnetic properties are discussed. (-) 1995 American Institute of Physics.
\end{abstract}

\section{INTRODUCTION}

Sm-Co thin films of high coercivities are attractive for high density hard disk magnetic recording media. ${ }^{1}$ Recently, as part of a program of pursuing high density recording me$\mathrm{dia}, \mathrm{Sm}-\mathrm{Co} / / \mathrm{Cr}$ thin films have been deposited by the dc magnetron sputtering technique and the microstructure has been studied by transmission electron microscopy (TEM). ${ }^{2}$ The coercivity varies with both film thickness and argon pressure. A high magnetic coercivity of $2.58 \mathrm{kOe}$ was obtained from a specimen processed at an argon pressure of 12 mTorr. High resolution electron microscopy (HREM) study shows that the microstructure of Sm-Co thin film is composed of the matrix and crystallites with a grain size of about $5 \mathrm{~nm}$. The matrix is amorphous and the crystallites are distributed discontinuously in the matrix. The crystal structure of the crystallites were studied by nanodiffraction (ND) and HREM. ${ }^{3}$ It was shown that the crystallites have a close packed structure with varying stacking mode from crystallite to crystallite. The TEM micrographs of the Sm-Co layer taken in bright field with a defocus of a few micrometers also revealed grain-like structure of about $25 \mathrm{~nm}$. This grain-like structure was found to be affected by the argon pressure. The higher the argon pressure, the larger the grain-like contrast becomes. $^{2}$

Two effects of the $\mathrm{Cr}$ underlayer on the magnetic film can be considered. One is that there may be a texture and epitaxial relation between the $\mathrm{Cr}$ underlayer and the $\mathrm{Sm}-\mathrm{Co}$ film. The other effect is that the morphology of the $\mathrm{Cr}$ underlayer may affect the structure of the Sm-Co film. This paper describes the result of TEM study on the morphology of the $\mathrm{Cr}$ underlayer and its effects on Sm-Co thin films.

s)Electronic mail: yliu@unlinfo.unl.edu

\section{EXPERIMENTAL PROCEDURE}

The Sm-Co thin films were prepared by the dc magnetron sputtering technique with varying argon pressures from 5 to 30 mTorr at room temperature. First, about $95 \mathrm{~nm}$ of $\mathrm{Cr}$ was deposited on $220 \mu \mathrm{m}$-thick glass substrate. The $\mathrm{Sm}-\mathrm{Co}$ films of different thickness from 6 to $96 \mathrm{~nm}$ were then deposited on the $\mathrm{Cr}$ layer under the same argon pressure. The average composition of the films found using energy dispersive $\mathrm{x}$-ray spectroscopy (EDX) in a scanning electron microscope was 79 at. \% Co, 21 at. \% Sm, which is very close to the target composition.

Plan view TEM samples three millimeters in diameter were drilled from the specimens. The disks were then dimpled from the substrate side to a thickness of $5 \mu \mathrm{m}$ at the center, followed by ion milling from the substrate side until perforation was just achieved. TEM observation of Sm-Co films was made using these samples. For observation of the microstructure of the $\mathrm{Cr}$ underlayer, the samples were further ion milled for 2-5 $\mathrm{min}$ from the $\mathrm{Sm}$-Co film side. Crosssection samples were prepared by embedding the strips of the films into a 3-mm-diameter Cu tube with EMbed 812 (supplied by Electron Microscopy Sciences, P.O. Box 251, Ft. Washington, Pennsylvania 19034). The $\mathrm{Cu}$ tube with the films was cross sectioned into about $0.3 \mathrm{~mm}$ slices. The slices were dimpled to $50 \mu \mathrm{m}$ at the center and then ion milled until perforation. The HREM and diffraction work was performed using a JEOL 2010 transmission electron microscope operating at $200 \mathrm{kV}$.

\section{RESULTS}

Figure 1 shows the bright field TEM images of the $\mathrm{Cr}$ underlayer as a function of defocus setting. The contrast of 

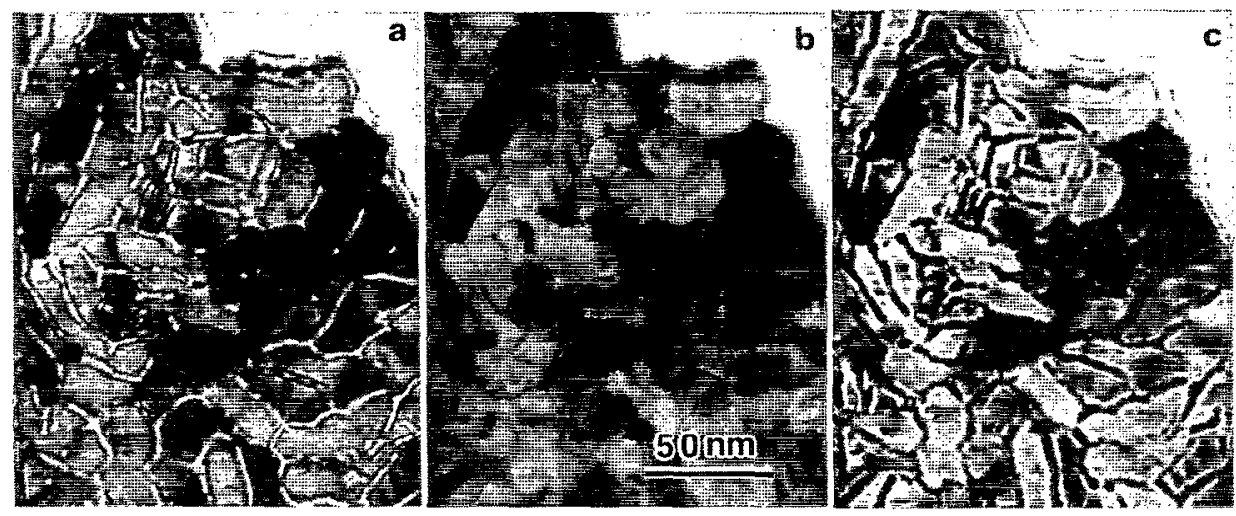

FIG. 1. Bright field TEM images of the $\mathrm{Cr}$ underlayer as a function of defocus. The argon pressure for deposition is $12 \mathrm{mTorr}$ (a) -2600 , (b) 0 , and (c) $+2600 \mathrm{~nm}$.

the grain boundaries at the in-focus image [Figure 1(b)] is small. The contrast of the grain boundaries is much enhanced by going out of focus. At underfocus the grain boundaries appear white [Fig. 1(a)] and at overfocus the grain boundaries black [Fig. 1(c)]. This contrast feature is the same as expected from Fresnel diffraction contrast (compare the contrast at the edge and at the grain boundaries). It is then suggested that there exist gaps at the grain boundaries.

The gaps at grain boundaries are better revealed by infocus HREM images. Figure 2 is a bright field TEM image showing where the HREM images were taken. Several grains indicated by the arrows appear dark because they were oriented on [111] zone axis. Such agglomerates composed of small tilt angle grains are frequently observed. The HREM images taken at [111] zone axis from grains indicated in Fig. 2 are shown in Figs. 3 and 4. As the images were taken at a defocus setting of about $-66 \mathrm{~nm}$ (second pass band), the white dots represent the projection of the atomic columns on (111) plane which have a separation of $0.236 \mathrm{~nm}$. In Fig. 3, the two grains have a small tilt angle. The gap which appears

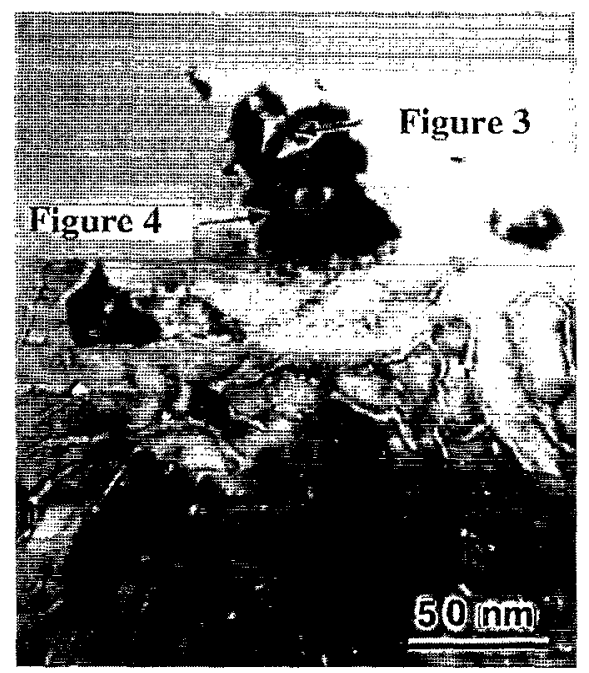

FIG. 2. Bright field TEM image of the $\mathrm{Cr}$ underlayer showing local small tilt angle grains. These grains are on [111] zone axis. HREM images of two local regions with grain boundary gaps and without grain boundary gaps are shown in Figs. 3 and 4, respectively. white is about $2 \mathrm{~nm}$ wide. In other grain portions the gaps are not observed. Figure 4 is an example in which no gaps are observed at the grain boundary. Therefore, the grain boundary gaps are sealed or connected at certain places on the $\mathrm{Cr}$ underlayer.

Some Sm-Co thin films of small thickness $(24 \mathrm{~nm}$ or smaller) deposited on the $\mathrm{Cr}$ underlayer at argon pressures of 12 mTorr (or higher) display similar grain-like contrast to that of the $\mathrm{Cr}$ underlayer in TEM bright field images. ${ }^{2}$ The higher the argon pressure, the more significant such contrast becomes. For this reason, a Sm-Co film deposited at argon pressure of $30 \mathrm{~m}$ Torr is chosen to demonstrate the grain-like contrast. The effect of defocus on the grain-like contrast for a

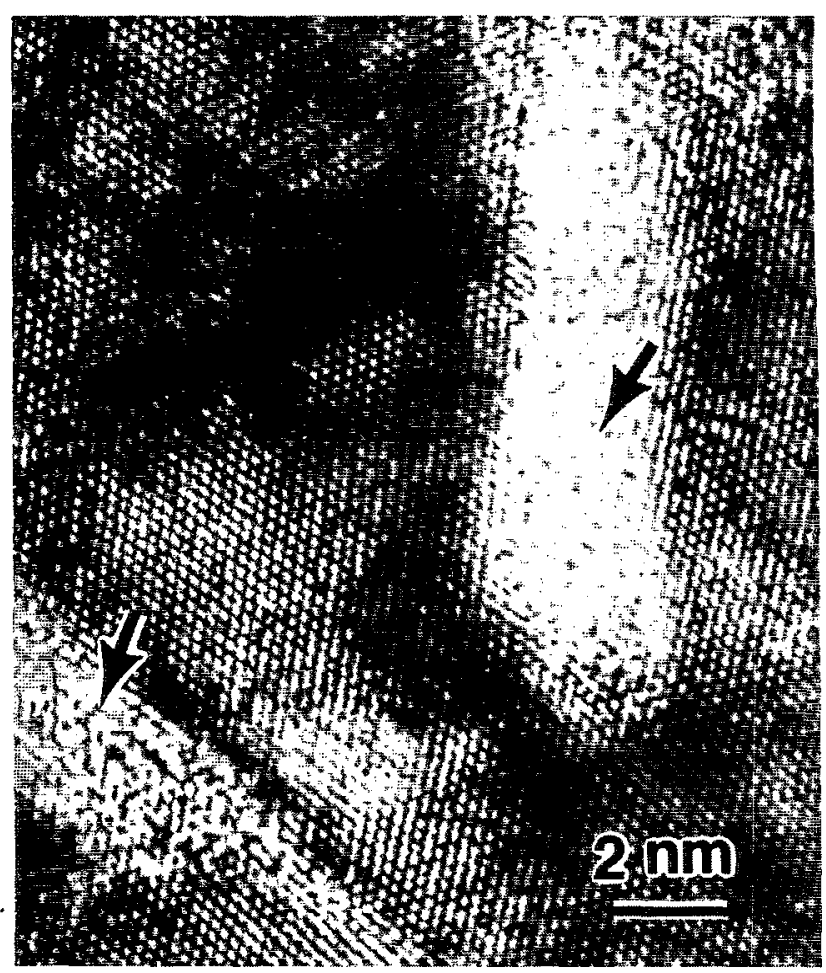

HTG. 3. HREM image of grain boundaries in the $\mathrm{Cr}$ underlayer showing two gaps as indicated by the arrows. 


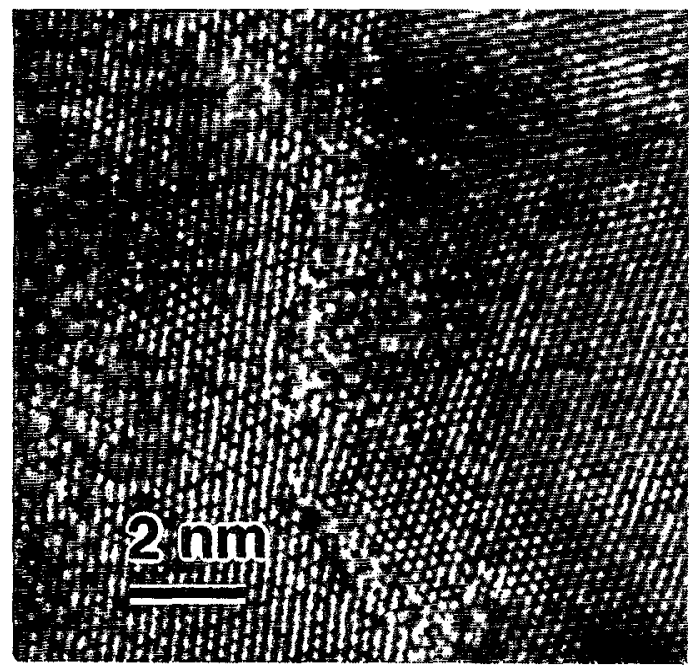

FIG. 4. HREM image of a small angle grain boundary in the $\mathrm{Cr}$ underlayer. No gaps are present.

film of $24 \mathrm{~nm}$ is shown in Fig. 5. The contrast feature is quite similar to that observed in Fig. 1, i.e., the grain-like contrast is about $25 \mathrm{~nm}$ in size and appears white in underfocas images and dark in overfocus images. However, one significant difference between Figs. 1 and 5 is that the $\mathrm{Cr}$ underlayer has a grain size of $25 \mathrm{~nm}$ while the Sm-Co film has a microstructure composed of crystallites of about $5 \mathrm{~nm}$ distributed in the amorphous matrix. Figure 6 is an example of HREM images showing the crystallites in the amorphous matrix. It is then clear that the grain-like contrast of $25 \mathrm{~nm}$ in Fig. 5 has little to do with the grain size of Sm-Co crystallites but is generated by the gaps inherited from the $\mathrm{Cr}$ underlayer. Such gaps are labeled $\mathrm{G}$ and the crystallites labeled $\mathrm{C}$ in Fig. 6. Therefore, the grain-like contrast in Sm-Co films is named a "cluster" structure. Each cluster is grown on a Cr grain and surrounded by the gaps inherited from the grain boundary gaps in the $\mathrm{Cr}$ underlayer.

Figure 7 compares the effects of the $\mathrm{Cr}$ underlayer on $\mathrm{Sm}$-Co films of different thicknesses. All the films were deposited under the same argon pressure of $12 \mathrm{mTorr}$ but with different thicknesses. The microstructure shown here is at the

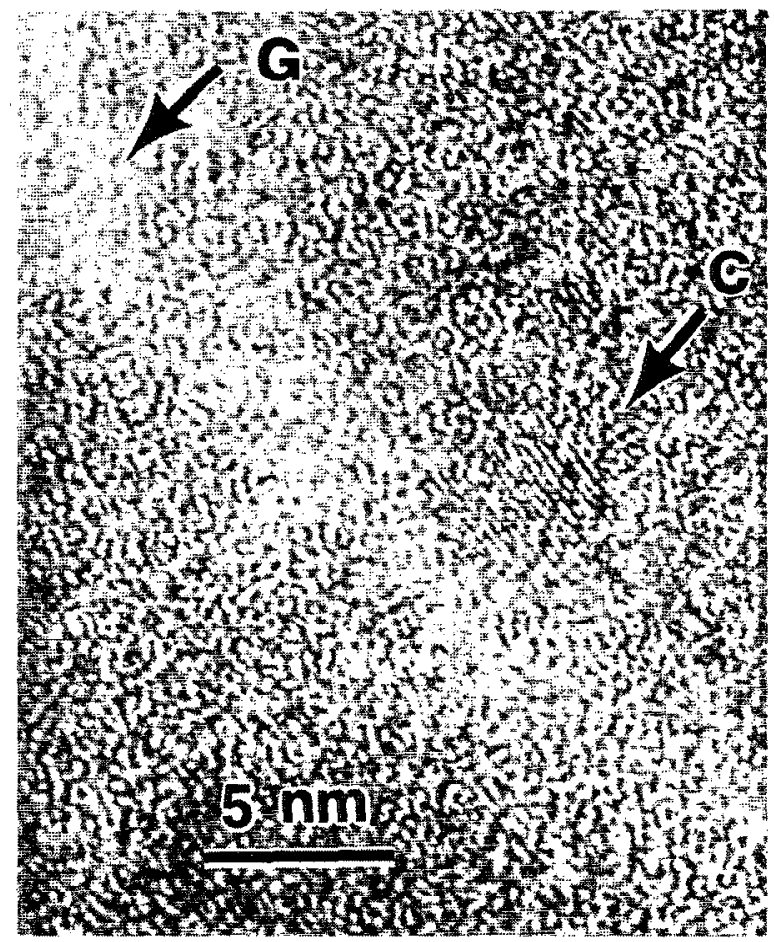

FIG. 6. HREM image of a Sm-Co film showing the crystallites in the amorphous matrix. The grain boundary gaps are indicated by letter $G$ and crystallites by letter $\mathrm{C}$.

top surface of each film. The microstructures have two contrast features. One is the grainy contrast of about $5 \mathrm{~nm}$ in all specimens and the other is the cluster structure of about 25 $\mathrm{nm}$. The grainy contrast is due to the crystallites of about 5 $\mathrm{nm}$ in size in Sm-Co film. The cluster structure of $25 \mathrm{~nm}$ is inherited from grain boundary gaps of the $\mathrm{Cr}$ underlayer. The cluster structure becomes less visible as the thickness increases and disappears in the film of thickness of $96 \mathrm{~nm}$. The inheritance of the grain boundary gaps is well revealed by cross section view which is shown in Fig. 8. Note that the $\mathrm{Sm}$-Co film has the grainy contrast of about $5 \mathrm{~nm}$ while the $\mathrm{Cr}$ underlayer does not (compare Figs. 1 and 7). A few grain boundary gaps inherited from the $\mathrm{Cr}$ underlayer are indicated by the arrows.

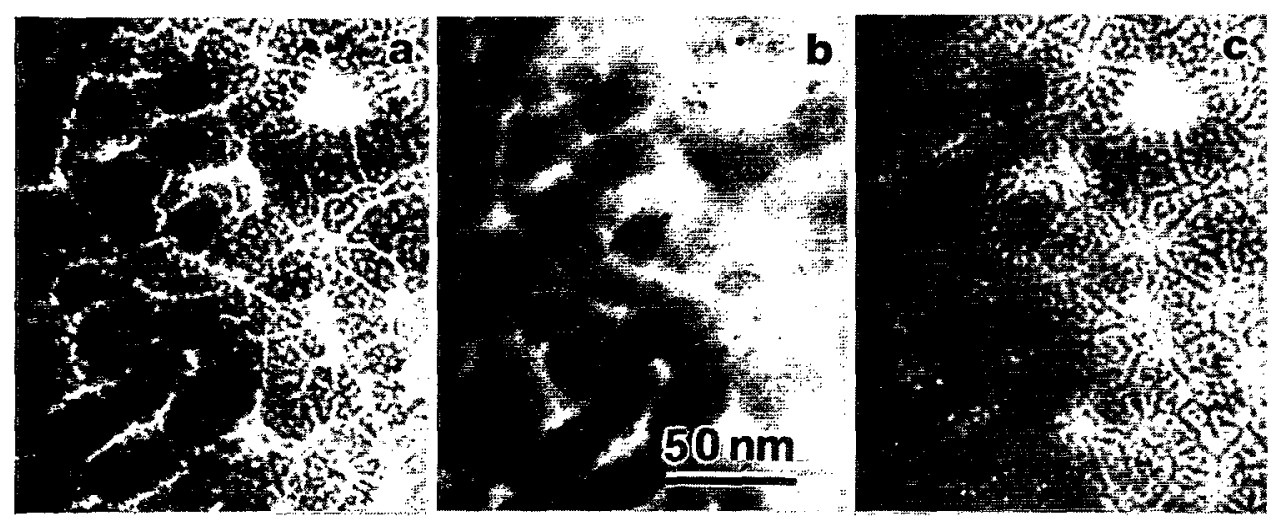

FIG. 5. Bright field TEM images of a Sm-Co film as a function of defocus. The argon pressure for deposition is $30 \mathrm{~m}$ Torr. (a) -2600 , (b) 0 , and (c) $+2600 \mathrm{~nm}$. 

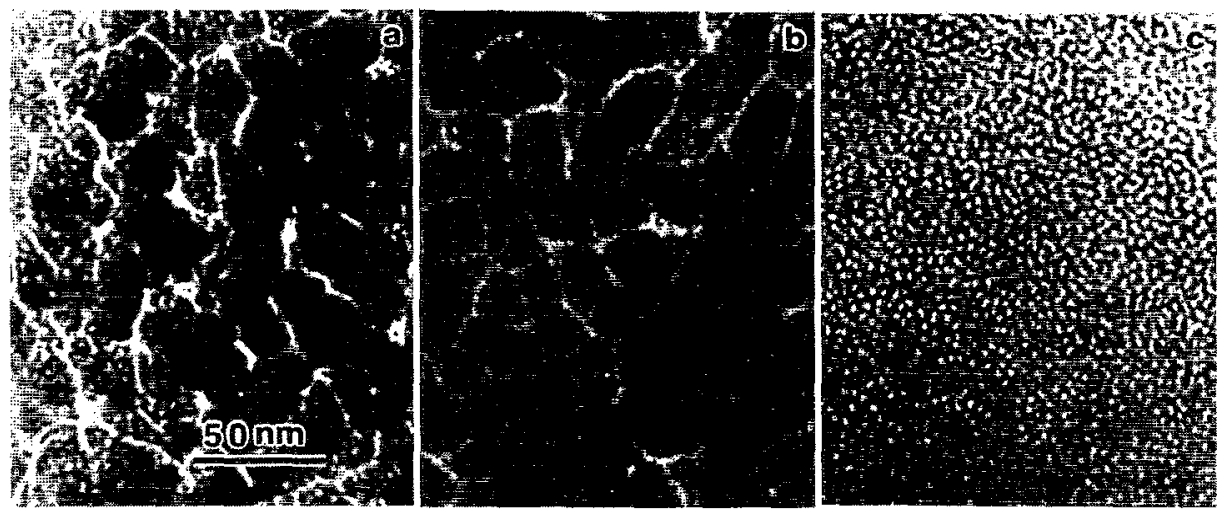

FIG. 7. Effect of the $\mathrm{Cr}$ underlayer on Sm-Co films of different thicknesses. (a) 6, (b) 24, and (c) $96 \mathrm{~nm}$.

\section{DISCUSSION}

Similar grain boundary contrast of the $\mathrm{Cr}$ underlayer has been observed, for example, by Nguyen $e t$ al. ${ }^{4}$ Similar contrast was also observed by Yamaguchi and Yanagisawa in magnetic thin films of $\mathrm{CoNi}^{5}{ }^{5}$ and by Yogi et al. in magnetic thin films of $\mathrm{CoPtCr}{ }^{6}$ There is a strong possibility that grain boundary gaps exist in the $\mathrm{Cr}$ underlayer in the films made by these authors. The contrast at grain boundaries in conventional material, where there exist no grain boundary gaps, will become diffused as defocus is made toward underfocus or overfocus.

It should be pointed out that in the defocused bright field images the white contrast at grain boundaries does not reflect the gap width. The gap width can only be measured in HREM images where the defocus is small (usually less than $100 \mathrm{~nm}$ toward under defocus). Another question on the grain boundary gaps is whether they are formed during specimen preparation process. The answer is that they are not. In the ion thinning process, the atoms on the surface are removed first. Grain boundary gaps have not been observed in any materials prepared by conventional processes such as arc melting or induction melting.

As observed in Fig. 8, the grains in the cross sectional view sample show columnar shape in the film normal direction. Such structure is frequently observed in directional solidification process. The grains growing into the columnar shape usually have a preferable crystallographic orientation. $\mathrm{Cr}$ (110) parallel film surface texture has been shown to exist in the $\mathrm{Cr}$ underlayer. ${ }^{7}$ However, there is a significant differ-

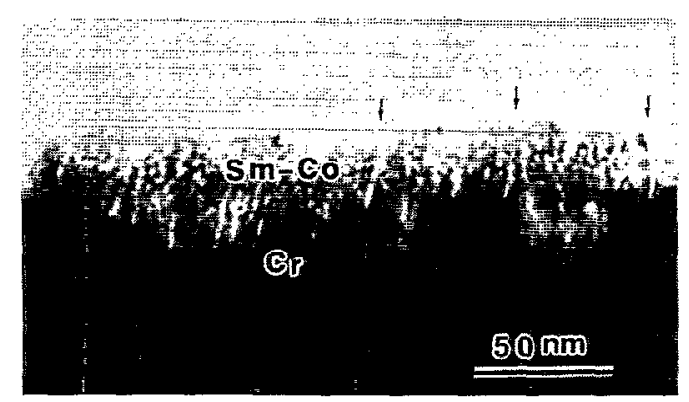

FIG. 8. Cross section view of a $\mathrm{Sm}$-Co film on the $\mathrm{Cr}$ underlayer. A few grain boundary gaps are indicated by the arrows. ence between directional solidification and sputter deposition. In directional solidification, the grains grow into the liquid and therefore no gaps at grain boundaries are formed. In the sputtering process, the grains grow by absorbing the in-coming atoms. The growing front is not smooth but stretches out at the center (this can be seen in Fig. 8 and also revealed by atomic force microscopy). Figure 9(a) schematically illustrates the growing process of the $\mathrm{Cr}$ grains. The grain boundary gaps are formed because each grain grows by itself. TEM examination of the $\mathrm{Cr}$ underlayer has shown that the higher the argon pressure in sputtering process, the more significant the grain boundary gaps are. ${ }^{2}$ Therefore, argon pressure has a strong effect on the formation of grain boundary gaps in the $\mathrm{Cr}$ underlayer. The effect of $\mathrm{Cr}$ underlayer on the formation of $\mathrm{Sm}$-Co films are schematically illustrated in Figs. 9(b) and 9(c). On each $\mathrm{Cr}$ grain, a cluster of Sm-Co is formed with gaps between adjacent clusters [Fig. 9(b)]. The clusters have a tendency to connect to each other as the
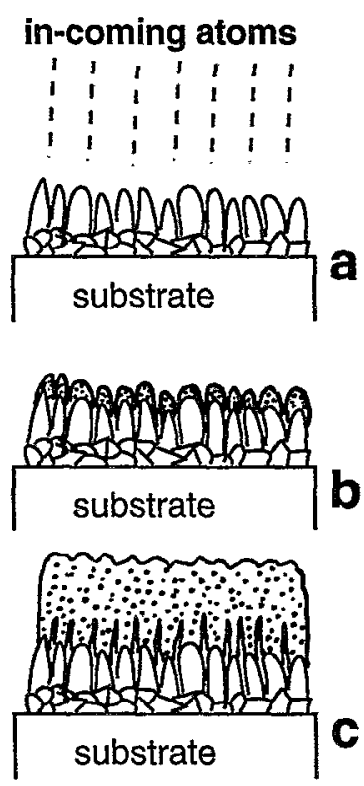

FIG. 9. (a) Schematic illustration of the formation of grain boundary gaps in the Cr underlayer, (b) morphology of Sm-Co films of smaller thickness (24 $\mathrm{nm}$ or smaller), (c) morphology of SM-Co films of greater thickness (96 nm or greater). 
deposition continues and eventually the gaps inherited from the $\mathrm{Cr}$ underlayer disappears (Fig. 9). This explains why the cluster structure is observed in Figs. 7(a) and 7(b) but not in Fig. 7(c) because the observation was made on the top layer of the films.

The effects of the $\mathrm{Cr}$ underlayer on the magnetic properties of Co-based films have been known for some time. The films deposited on the $\mathrm{Cr}$ underlayer show much higher coercivity and anisotropy than films deposited on glass. (110) texture of the $\mathrm{Cr}$ underlayer has been reported and considered the reason of such high coercivity and anisotropy. ${ }^{8,9}$ The effects of $\mathrm{Cr}, \mathrm{Mo}$, and $\mathrm{W}$ underlayer morphology on magnetic properties were investigated by Nguyen et al. ${ }^{14}$ They found the noise performance of the $\mathrm{CoPtCr}$ films decreases from $\mathrm{Cr}$, to Mo to W which are used as the underlayers. Also the noise performance improves for all underlayers as the argon pressure goes higher. The noise improvement was suggested to be due to isolation of the magnetic grains. Similar results of argon pressure on noise reduction were also obtained for CoNiCr films on the $\mathrm{Cr}$ underlayer. ${ }^{10}$ The morphology of the $\mathrm{Cr}$ underlayer and the Sm-Co film observed in this study shows similarity to the microstructures observed in early studies. However, the grain-like contrast in the 'lEM bright field images is not a direct evidence of magnetic grains. Therefore it has been named cluster structure as it is simply inherited from the grain boundary gaps of the $\mathrm{Cr}$ underlayer. The gaps in magnetic films inherited from the $\mathrm{Cr}$ underlayer may weaken the interaction between different clusters and therefore reduce noise when used as a magnetic recording medium.

\section{CONCLUSIONS}

The microstructure of the $\mathrm{Cr}$ underlayer in $\mathrm{Sm}$-Co thin films and its effect on Sm-Co thin films were studied by transmission electron microscopy. The following results were obtained.

(1) The grain size of the $\mathrm{Cr}$ underlayer is about $25 \mathrm{~nm}$. Grains with small angle misorientation usually form local agglomerates.

(2) A large proportion of the grain boundaries have gaps.
Such gaps at grain boundaries form white contrast at underfocus settings and black contrast at overfocus settings in TEM bright field inages. The gap width (about 1-3 nm) varies from place to place.

(3) The Sm-Co films deposited on $\mathrm{Cr}$ underlayers inherit similar grain-like contrast of about $25 \mathrm{~nm}$. Such contrast is produced at positions adjacent to the grain boundary gaps of the $\mathrm{Cr}$ underlayer suggesting a similar gap structure in the Sm-Co film. However, such contrast becomes weak as the thickness of the film increases and disappears at a thickness of $96 \mathrm{~nm}$. The gaps in Sm-Co films may have a significant effect on the magnetic domain formation and interaction between adjacent magnetic domains.

\section{ACKNOWLEDGMENTS}

The authors thank Todd Voiles of Central Facility for Electron Microscopy, University of Nebraska-Lincoln, for maintaining the TEM and other related facilities in good condition. This work is made possible by ARPA/NSIC under Grant MDA 972-93-1-0009.

${ }^{1}$ E. M. T. Velu and D. N. Lambeth, IEEE Trans. Magn. MAG-28, 3249 (1992).

${ }^{2}$ Y. Liu, B. Robertson, Z. S. Shan, S. Malhotra, M. J. Yu, S. K. Renukunta, S. H. Liou, and D. J. Sellmyer, IEEE Trans. Magn. 6, 4035 (1994).

${ }^{3}$ Y. Liu, B. Robertson, Z. S. Shan, S. H. Liou, and D. J. Sellmyer, Electron Microscopy 1994, Proceedings of the 13th International Congress on Electron Microscopy, Vol. 2B, p. 1187.

${ }^{4}$ T. A. Nguyen, T. Yogi, and S. Lambert, Proceedings of EMSA, edited by G. W. Bailey and E. L. Hall (San Francisco Press, San Francisco, 1991), p. 758.

${ }^{5} \mathrm{H}$. Yamaguchi and M. Yanagisawa, IEEE Trans. Magn. MAG-22, 576 (1986).

${ }^{6}$ T. Yogi, T. A. Nguyen, S. E. Lambert, G. L. Gorman, and G. Castillo, IEEE Trans. Magn. MAG-26, 1578 (1986).

${ }^{7}$ L. Tang, G. Thomas, M. R. Khan, and S. L. Duan, Proceedings of EMSA, edited by G. W. Bailey and E. L. Hall (San Francisco Press, San Francisco, 1991), p. 580.

${ }^{8}$ T. Lin, R. Alani, and D. N. Lambeth, J. Magn. Magn. Mater. MAG-78, 213 (1989).

${ }^{9}$ K. Hono, B. Wong, and D. E. Laughlin, J. Appl. Phys. 68, 4734 (1990).

${ }^{10}$ R. Ranjan, J. A. Christner, and D. P. Ravipati, IEEE Trans. Magn. MAG26, 322 (1990). 